\title{
Medios audiovisuales en la enseñanza universitaria de la historia. Análisis del documental: Hans Hutter: un suizo en la guerra civil española
}

\author{
Luis M. Calvo Salgado ${ }^{1}$ \\ Profesor (Obereassistent) y coordinador de la reforma de Bolonia \\ Universidad de Zúrich
}

\begin{abstract}
Audiovisual media and teaching history in the university: analyse of the documentary film: Hans Hutter. A Swiss volunteer in the Spanish Civil War
\end{abstract}

\begin{abstract}
RESUMEN
Los medios audiovisuales pueden estar presentes en la enseñanza de la Historia

a nivel universitario desde los primeros cursos. Esta es la apuesta del Seminario de Historia de Zúrich, que, con motivo de la implantación de la reforma de Bolonia, se ha propuesto integrarlos en una plataforma de e-learning pensada para esta primera fase de los estudios. Para ello se han rodado películas cortas que se muestran en la plataforma sobre los siguientes temas: qué es la Historia; cómo buscar bibliografía en una biblioteca; cómo presentar una ponencia; qué es una fuente; qué función social tienen los archivos y cómo se trabaja en ellos. Finalmente, se utiliza un documental (que se ofrece como complemento de este número de la revista) para conjugar el uso de entrevistas de historia oral, de películas de archivo y de fotografías.
\end{abstract}

\begin{abstract}
Since the first courses audiovisual media can be present in academical history education. This is the application of Zurich's Institute of History, which due to the introduction of the Bologna process has intended to integrate them into an elearning platform preconceived for this first level of study. For this purpose short movies have been filmed, which are showed on the platform on the following subjects: What is history? How to find a bibliography in a library; How to give a presentation; What is a source? What are the archives' social functions and how do we work with them? Finally, a documentary film (offered as a supplement to this review volume) is used in order to combine the use of oral history interviews, archive movies and pictures.
\end{abstract}

\footnotetext{
1 Se adjunta DVD con documental en la portadilla de la revista.
} 


\author{
PALABRAS CLAVE \\ E-learning, Suiza, Guerra Civil española \\ Voluntarios suizos, Fuentes de historia \\ oral, Películas.
}

KEY WORDS

E-learning, Switzerland, Spanish Civil

War, Swiss volunteers, oral history

sources, film.

En el semestre de invierno de 2006 a 2007, la Facultad de Filosofía de la Universidad de Zúrich comenzó a ofrecer los primeros módulos de los nuevos planes de estudios conducentes a la obtención de títulos universitarios oficiales de Grado en aplicación de las normas del proceso de Bolonia. Desde 2004 participé, desde mi puesto de coordinador de la reforma de Bolonia en el Seminario de Historia de esta Facultad, ${ }^{2}$ en la presentación de propuestas para la elaboración de los planes de estudios en las materias de Historia y desde entonces me ocupo, entre otras cosas, de coordinar la programación de las materias adaptadas al sistema de créditos europeos, conocido como ECTS (European Credits Transfer System). Dado que los objetivos formativos de las enseñanzas de Historia deben integrar competencias genéricas básicas, competencias transversales y competencias específicas que permitan a los futuros historiadores orientarse profesionalmente para integrarse luego en el mercado de trabajo, ha sido necesario diseñar nuevos contenidos concretando los conocimientos, aptitudes y destrezas que los estudiantes deben adquirir. Para el diseño de los nuevos contenidos de los tres primeros semestres se constituyó una comisión formada por docentes y estudiantes, de la que, por mi cargo, también formé parte, y que elaboró una serie de propuestas concretas aprobadas posteriormente por el órgano de gobierno del Seminario de Historia. ${ }^{3}$ A continuación trataré de explicar cómo hemos tratado de integrar los medios audiovisuales en estos tres primeros semestres de los estudios de Historia. Uno de los proyectos más importantes y prometedores que acompañaron la elaboración de esos nuevos contenidos para los tres primeros semestres fue una plataforma de e-learning pensada para el uso de los docentes y de los estudiantes en esa fase inicial de sus estudios. La comisión ya aludida se ocupó de supervisar los contenidos de la plataforma que incluye textos, imágenes y medios audiovisuales. La plataforma está concebida para combinar los contenidos de e-learning con la presencia en las clases; no trata, por lo tanto, de sustituir la interacción de los estudiantes con los docentes sino de completarla. El acceso a la plataforma lo obtienen los docentes y los estudiantes con un código que adquieren al trabajar o estudiar en la Universidad. ${ }^{4}$ No es posible detallar aquí el contenido de esos tres

${ }^{2}$ El puesto recibe el nombre oficial de «Oberassistent» en alemán e incluye tareas de gestión, de docencia y de investigación.

${ }_{3}^{3}$ La comisión fue presidida por el profesor de Historia Contemporánea Philipp Sarasin y en ella participaron, entre otras personas, profesoras de Historia Antigua, Anne Kolb, Historia Medieval, Claudia Zey, e Historia del Este de Europa, Nada Boskovska. El director del Seminario de Historia ha sido en esta etapa el también profesor de Historia Contemporánea Carlo Moos.

${ }_{4}^{4}$ Para aquellos docentes universitarios de Historia que estén interesados en ver la plataforma de elearning es posible, en ciertos casos, ofrecer un acceso limitado en el tiempo con el fin de que puedan conocerla. Para ello pueden dirigirse al autor de este artículo. 
primeros semestres, y por ello me limitaré a explicar en qué medida y de qué modo utilizamos medios audiovisuales dentro de la plataforma de Internet ya aludida, para luego concentrarme en la presentación de un documental que hemos realizado con fines didácticos sobre un brigadista suizo que participó en la Guerra Civil española y que también se puede ver en dicha plataforma. ${ }^{5}$ En el primer semestre, los estudiantes tienen un módulo que consta de dos elementos: un proseminario, es decir, un curso preparatorio en que se aprenden las técnicas básicas de búsqueda de información en bibliotecas y de redacción de trabajos en la Universidad, y una lección magistral, en la que participan todos los catedráticos, de manera que los estudiantes puedan ir conociendo cuáles son las líneas básicas de docencia más importantes que se van a encontrar en sus estudios. El proseminario comienza con la pregunta: ¿Qué es la Historia? Antes de debatir sobre este tema y de escribir textos cortos sobre el mismo se puede comenzar leyendo textos de autores importantes con carácter introductorio que se recomiendan en la plataforma. ${ }^{6}$ Pero, además, hemos querido que hubiese una percepción más cercana de las opiniones de nuestros docentes, y varios catedráticos de nuestra institución se han mostrado dispuestos a responder a tres preguntas ante la cámara: ${ }^{7}$

- ¿Qué es la Historia?

- ¿Qué es más importante en la Historia, los acontecimientos o las estructuras? día?

- ¿Qué importancia tiene, desde su punto de vista, la ciencia histórica hoy en

Las respuestas de cada profesor duran unos diez minutos en total, es decir, cada uno habla unos tres minutos por pregunta. Los estudiantes pueden ver las películas en su ordenador o el docente puede, naturalmente, decidir proyectar alguna de las películas en clase para hablar de ellas con los alumnos a continuación. La universidad pone también salas de ordenadores a disposición de los alumnos en las que se puede usar Internet y por lo tanto utilizar la plataforma. En cualquier caso, la finalidad consiste en que los alumnos vean desde el principio la pluralidad de las opiniones existentes sobre el tema, que las puedan comparar y que saquen sus propias conclusiones. Para ello, la plataforma ofrece a los docentes y a los estudiantes diversas posibilidades de comunicación como, por ejemplo, foros de discusión en los que los alumnos pueden dar su opinión sobre las respuestas de los profesores o participar en discusiones sobre el tema con sus compañeros o con sus docentes. Para la elaboración de las películas, en este caso de factura muy sencilla, pues se trata de entrevistas a los profesores en sus despachos, contamos

${ }^{5}$ El documental en DVD se ofrece como complemento de este número de la revista.

${ }^{6}$ Se trata de textos de Marc Bloch, Paul Veyne, Volver Selin, Hans-Werner Goetz, Eric Hobsbawn o Joan Scott.

7 Son los profesores Nada Boskovska, Jörg Fisch, Gesine Krüger, Franziska Loetz, Philipp Sarasin, Jakob Tanner y Claudia Zey. 
con la colaboración del departamento de la Universidad de Zúrich «Multimedia y Servicios de E-learning». Este departamento apoya y asesora a los docentes en lo relativo a la preparación didáctica de contenidos en medios de comunicación modernos. Su oferta va desde la producción de contenidos multimedia hasta la infraestructura para la grabación de películas didácticas. Yo me ocupé de coordinar el trabajo de colaboración entre los docentes de nuestro seminario, por un lado, y los técnicos del departamento Multimedia, por otro. En el primer proseminario, los estudiantes reciben, por otro lado, una formación básica en lo referido a la búsqueda de bibliografía con medios tradicionales y modernos. Por un lado, se organizan visitas en la biblioteca del Seminario de Historia en las que las bibliotecarias (en la actualidad son todas mujeres) explican cómo está concebida la biblioteca y cuáles son las normas de uso. Lo mismo se hace en la Biblioteca Central, que es la biblioteca más importante del cantón de Zúrich. ${ }^{8}$ En colaboración con sus responsables de información, hemos organizado, como complemento de estas visitas, unos cursos de dos horas en los que los bibliotecarios presentan las nuevas posibilidades de uso de bancos de datos que contienen textos completos de revistas científicas, de manera que los estudiantes vayan conociendo desde el principio las suscripciones electrónicas por las que paga la Universidad. Para familiarizar mejor a los alumnos con el uso de la biblioteca del Seminario de Historia, hemos decidido rodar una película con un contenido explicativo muy parecido al de las visitas guiadas, porque la experiencia nos muestra que muchas cuestiones se plantean más de una vez, aun cuando hayan sido explicadas durante la visita y aunque las informaciones se presenten por escrito en la plataforma. Para ello hemos contado con la colaboración de las bibliotecarias, asumiendo incluso una de ellas, Hana Ribi, la dirección de la película por tener experiencia profesional en ese campo y escribiendo otra, Ariane Winkler, el guión, que ha conseguido aunar lo informativo y lo ameno. Para la grabación y el trabajo del rodaje contamos de nuevo con la colaboración del departamento Multimedia. Yo me he ocupado de la producción en este caso, ya que la película entrañaba una mayor complejidad que las anteriores por la cantidad de personas que participaban en ella tanto delante como detrás de la cámara. La película se muestra en estos momentos no sólo en la plataforma de e-learning, sino también en la página de Internet del Seminario de Historia, a la que cualquiera puede acceder libremente, porque se ha considerado que podía ser útil no sólo para los estudiantes de los primeros semestres sino también para los demás. ${ }^{9}$ Una de las destrezas que deben adquirir los estudiantes en sus estudios consiste en la capacidad de presentar ponencias de manera correcta, y ésta se ejercita ya desde el primer proseminario. También en este caso hemos pensado que una película podía contribuir a evitar errores y mejorar la técnica para hablar en público. Para ello elaboré un proyecto junto con la actriz e historiadora Myriam Spörri. El proyecto tuvo además el asesoramiento del Departamento de Didáctica Universitaria (Arbeitsstelle für Hochschuldidaktik), que juzgó el resultado tan posi-

8 http://www.zb.uzh.ch/

9 http://www.hist.uzh.ch/bibliotheken/histobib600.mov 
tivamente que decidió ofrecerlo como ejemplo en su página de Internet, de manera que también esta película puede verse no sólo en la plataforma sino también en acceso abierto a cualquier usuario de la red. ${ }^{10} \mathrm{La}$ actriz actúa en esta película como una ponente en una clase de Historia en la Universidad y muestra, en la primera parte, de unos siete minutos de duración, un ejemplo de cómo se puede presentar una ponencia de manera correcta y, en la segunda, también de siete minutos, escenifica varios tipos de errores muy frecuentes: la falta de contacto visual con el público, un uso inadecuado del soporte visual, una actitud poco apropiada a la situación o la falta de tiempo para terminar de decir lo que se quería contar. El contenido de la ponencia es en ambos casos el mismo, con una introducción, un cuerpo central y una conclusión, aunque no se muestran estas partes en toda su duración. La actriz, que al mismo tiempo es historiadora, habla sobre un tema que conoce muy bien: la historiografía sobre la República de Weimar. Pero, en la plataforma, se recomienda a los docentes utilizar la película como un estímulo para discutir con los alumnos sobre la calidad de las ponencias en el entorno universitario, concentrándose en los aspectos técnicos y no de contenido. En el segundo proseminario, el del segundo semestre, se aborda el tema de las fuentes y su uso para escribir Historia. Al final del proseminario los alumnos deben escribir un pequeño trabajo en el que analizan una fuente contextualizándola y mostrando que saben utilizar los métodos de la crítica de fuentes. Nos hemos esforzado especialmente por mostrar la amplitud de las fuentes históricas, otorgando especial atención a las imágenes y a los documentos audiovisuales. En primer lugar, se plantea de nuevo al comienzo del proseminario el problema de la definición del término: ¿Qué es una fuente? En este caso, quienes dan respuesta a la pregunta en películas de corta duración, aproximadamente unos cinco minutos, son otros docentes distintos a los que participaron en las entrevistas hechas para el primer proseminario, y que también se han prestado voluntariamente para el rodaje. ${ }^{11} \mathrm{Al}$ igual que en el caso anterior, en esta ocasión se pretende hacer hincapié en las diferentes definiciones que dan los entrevistados para así fomentar discusiones y debates tanto por escrito, en un foro de la plataforma pensado para ello, como oralmente durante las clases. Son películas que consisten, como las de la definición de la Historia, en una entrevista en un despacho y para las que se contó de nuevo con el asesoramiento y el apoyo técnico ya citados. Mi labor fue de coordinación y elaboración del proyecto.

Uno de los aspectos más importantes del segundo proseminario es la colaboración de la Universidad con algunos de los archivos más importantes de Zúrich, que nos permite organizar visitas guiadas para los estudiantes pensadas específicamente para futuros historiadores. Junto con los archiveros hemos desarrollado una serie de informaciones y ejercicios que se ofrecen en la plataforma de Internet, de modo que las visitas reales puedan ser preparadas por los estudiantes de an-

10 http://www.afh.uzh.ch/medien/referieren.html

11 Se trata de Christian Koller, Martin Lengwiler, Paolo Ostinelli y Stefan Sonderegger. 
temano contando con materiales que los archivos han puesto a su disposición. De este modo, las visitas no quedan como hechos aislados, sino que se integran en los cursos y contribuyen a confrontar a los alumnos con un lugar de trabajo tan esencial para estudio de la Historia como son los archivos. Uno de estos archivos con los que colaboramos, el Archivo de Historia del tiempo presente del Instituto Politécnico de Zúrich (Archiv für Zeitgeschichte der ETH), ofrece en su página de Internet, por cierto, una película de presentación que fue realizada con anterioridad a nuestro proyecto, pero que también utilizamos con los grupos que lo visitan. ${ }^{12}$

Por otro lado, hemos contado para la elaboración de la plataforma con la ayuda de Memoriav, la red de los archivos, bibliotecas y museos suizos encargada del mantenimiento y la difusión de las fuentes audiovisuales. El historiador Felix Rauh, de Memoriav, ha trabajado con nosotros para ofrecer materiales audiovisuales en la plataforma y para elaborar el material didáctico correspondiente. Así, es posible aprender cómo encontrar documentos audiovisuales en la base de datos de Memoriav, llamada Memobase, es decir, vídeos, películas, grabaciones de radio o fotografías; ${ }^{13}$ cómo trabajar con ellos interpretando informaciones adicionales sobre los contextos en que surgieron o se usaron y evaluando la validez y utilidad de su información; y, finalmente, hacer ejercicios partiendo de dos ejemplos muy distintos sobre los que se facilita la información paralela necesaria para la crítica de fuentes: una película de la información semanal en los cines suizos del año 1942 y unas imágenes de un telediario suizo del 31 de mayo de 1980. Memoriav ofrece, además, su apoyo a los docentes que utilizan estos materiales en el caso de que necesiten ayuda para explicar las características y la problemática de este tipo de fuentes. Para que los alumnos conozcan también los excelentes ejemplos de fuentes audiovisuales francesas disponibles en Internet gracias al Institut National de l'audiovisuel, preparamos ejercicios para la plataforma en los que pueden aprender a utilizar mejor las noticias y documentales que se encuentran en la página «Jalons pour l'histoire du temps présent». ${ }^{14}$

Como complemento de las visitas a los archivos hemos realizado un debate en un estudio de televisión de la Universidad con los representantes de cuatro de los archivos suizos más importantes, para debatir con ellos sobre temas relativos a la función social y al trabajo de sus instituciones. En el debate participaron el director del Archivo Federal Suizo (Schweizerisches Bundesarchiv) Andreas Kellerhals; el director del Archivo Cantonal de Zúrich (Staatsarchiv des Kantons Zürich), Beat Gnädinger; el director interino del Archivo Social Suizo (Schweizerisches Sozialarchiv) Urs Kälin; y el director interino del Archivo de Historia del tiempo presente del Instituto Politécnico de Zúrich (Archiv für Zeitgeschichte der ETH), Daniel Nerlich. Yo asumí la preparación y moderación del debate, que dura 52 minutos si se

\footnotetext{
12 http://www.videoweb.ethz.ch/video/AfZ/AfZ_de.html. De esta película existe también una versión en inglés y otra en francés.

13 http://de.memoriav.ch/

14 http://www.ina.fr/archives-tele-radio/professionnels/jalons.html
} 
quiere ver entero, pero que puede ser visto también sólo por partes escogiendo las respuestas que uno quiere gracias a un menú de elección. De este modo se puede saltar de un capítulo a otro. Las preguntas tratadas y los minutos que duran las respuestas de los participantes en el debate son las siguientes:

- ¿Cuáles son los tipos de fondos documentales de los que dispone su archivo? (7 minutos).

- ¿Según qué criterios se decide aumentar el volumen de un determinado tipo de documentación? (12 minutos).

- ¿Cómo buscan ustedes establecer contacto con grupos específicos de público y con la opinión pública en general? (6 minutos).

- ¿Cómo definen a sus grupos de usuarios? (7 minutos).

- ¿Cómo se dan a conocer los trabajos que surgen a partir de investigaciones en sus archivos? ¿Tienen sus instituciones series en las que se puedan publicar? (3 minutos).

- ¿Qué nos pueden decir sobre el registro de sus fondos con medios informáticos y de su presentación en sus archivos? (8 minutos).

- ¿Cómo ven ustedes el problema de archivar grandes cantidades de datos digitales? (9 minutos).

El documental: Hans Hutter: un suizo en la Guerra Civil española. Al margen de las películas didácticas elaboradas específicamente para la plataforma y apoyadas por el servicio Multimedia de la Universidad, realicé, junto con mi colega Christian Koller, un documental sobre un brigadista suizo, Hans Hutter, en la Guerra Civil española. ${ }^{15}$ Nuestro documental surgió a partir de un seminario sobre la Guerra Civil española en su contexto internacional que dirigimos Christian Koller y yo en el semestre de invierno del 2004 al 2005 en la Universidad de Zúrich. Nosotros somos ante todo historiadores y este era nuestro primer documental, así que se trataba de un desafío arriesgado pero que resultó finalmente, para nosotros, muy enriquecedor e interesante. En aquel seminario, una de las estudiantes nos preguntó si podíamos invitar a Hans Hutter para hablar con los alumnos, porque ella conocía a su familia. Nosotros habíamos leído sus memorias y aceptamos enseguida su propuesta. ${ }^{16}$

Cuando Hans Hutter vino a nuestro seminario hicimos una primera grabación consistente en filmar su conversación con los alumnos. Les explicó su historia primero y luego respondió a sus preguntas. Así empezamos a pensar en hacer

\footnotetext{
15 Nosotros hemos financiado y dirigido el documental, en el que han participado Reto Stamm, detrás de la cámara y con el sonido, Rolf Frei, en el montaje, y Nicole Marti, que puso la voz en off.

${ }^{16}$ HUTTER, Hans: Spanien im Herzen. Ein Schweizer im Spanischen Bürgerkrieg. Bearbeitung : André Hermann. Mit einem Geleitwort von Bundesrätin Ruth Dreifuss und einem Nachwort von Walther $L$. Bernecker. Zúrich, Rotpunktverlag, 1996.
} 
este documental, ese fue en realidad el comienzo. Durante los dos años siguientes nos encontramos con Hans Hutter cuando tenía tiempo y fuerzas, puesto que estaba ya muy mayor y no siempre se encontraba bien. Cuando empezamos tenía 91 años y acabamos la película poco antes de que se muriese a los 93 años en el mes de diciembre de 2006. Logramos que la viese, y le emocionó mucho, según nos dijeron los familiares y amigos íntimos que estaban en esos momentos con él.

Dentro del segundo proseminario, en el que se trata el tema de las fuentes, ofrecemos partes dedicadas a las características específicas de las fuentes en la Edad Antigua, la Edad Medieval y la Moderna y Contemporánea. Para la parte de las fuentes en Historia Contemporánea decidimos ofrecer nuestro documental en la plataforma, porque se trataba de dar un ejemplo de cómo conjugar entrevistas de historia oral, películas de archivo y fotografías. Cuando presentamos la película en este tipo de proseminarios nos centramos en los aspectos relacionados con los tipos de fuentes ya citados. Pero, naturalmente, también organizamos a veces cursos sobre la Guerra Civil española, como el seminario en el que surgió la idea de hacer el documental, y en estos casos el documental sirve para ahondar en la cuestión de los brigadistas suizos. Además hemos podido mostrar el documental en diversas universidades e institutos suizos así como en centros culturales, casi siempre acompañando la proyección de un debate con el público. En España, el documental se presentó hasta ahora el 22 de octubre de 2007 en la Universidad de Almería en el ciclo "Cine, dictadura y derecho" invitados por el profesor Federico Fernández-Crehuet, el 30 de noviembre de 2007 en la Filmoteca Nacional, también con un debate al final, y el 29 de enero en un seminario de la Facultad de Bellas Artes de la Universidad Complutense organizado por Dolores Fernández y Pilar Montero. En cada uno de estos casos, las preguntas y el debate con el público fueron muy diferentes, dependiendo de los intereses de los espectadores.

A continuación me ocuparé del documental con una pequeña introducción sobre los voluntarios suizos en la Guerra Civil, abordando luego la memoria histórica en relación a la participación de los brigadistas en la Guerra, la historia de Hans Hutter en particular y los elementos de los que consta el documental, haciendo especial hincapié en las fotografías de Hans Hutter que aparecen en la película.

\section{LOS SUIZOS EN LA GUERRA CIVIL ESPAÑOLA}

El mecánico de coches, Hans Hutter, nacido en 1913 y que no pertenecía a ningún partido político, y su hermano Max, que cayó en el frente de Madrid, eran dos de los 815 suizos que lucharon del lado republicano entre 1936 y 1938. A ellos hay que añadir unos 30 voluntarios suizos que se unieron a las tropas franquistas. Las Brigadas Internacionales son, después de la Legión Extranjera, en la que desde 1831 sirvieron entre 30.000 y 40.000 suizos, y las SS alemanas durante la 
Segunda Guerra Mundial, que atrajeron a unos 900 voluntarios suizos, la unidad militar que, en tercer lugar, más voluntarios suizos atrajo en los siglos XIX y XX. ${ }^{17}$

De los suizos que lucharon en las Brigadas Internacionales el 59 ' $8 \%$ eran miembros del Partido Comunista o de su organización juvenil, el 12,1\% miembros del Partido Socialdemócrata o de su organización juvenil, el 3,6\% anarquistas, el 2,3\% ex-miembros del Partido Comunista, el 1,5\% ex-miembros del Partido Socialdemócrata y el 0'9\% trotskistas. Los comunistas, por lo tanto, estaban más representados que en la media de los otros países. La edad media era de 27 años y la mayoría eran solteros. El número de caídos no se puede conocer con exactitud, pero se encuentra entre el 20 y el $26 \%$. Aproximadamente la mitad de los supervivientes sufrió heridas. ${ }^{18}$

Suiza fue la única democracia cuya justicia persiguió a los voluntarios de la Guerra Civil de manera sistemática. Ya la constitución federal de 1848 prohibía acuerdos militares con otros países, sin suprimir los que entonces existían. En 1859 se prohibió además por ley el enrolamiento individual en «tropas extranjeras, no nacionales»; la prohibición fue, de todos modos, interpretada de modo muy laxo. En 1927, la legislación penal militar prohibió de manera general el servicio militar en el extranjero (Art. 94). Poco después del comienzo de la Guerra Civil española, el Consejo Federal, es decir, el gobierno del país, prohibió la exportación de material de guerra de cualquier tipo a España, la salida del país para participar en la Guerra Civil española así como la pérdida del tiempo obligatorio en el servicio militar suizo, concretamente los cursos de entrenamiento, por ausencia del país. En total fueron 550 los voluntarios suizos en España los perseguidos penalmente y 420 los condenados. La duración del encarcelamiento iba de 15 días a cuatro años; el $81 \%$ de los condenados recibieron penas de cárcel de entre uno y seis meses. En la mayor parte de los casos, la pérdida de libertad fue acompañada de una pérdida de derechos políticos de entre uno a cinco años. ${ }^{19}$

\section{LA MEMORIA HISTÓRICA DE LA PARTICIPACIÓN EN LAS BRIGADAS INTERNACIONALES}

Poco después de la Guerra Civil, los voluntarios suizos escribieron algunos libros de memorias. Tras muchos años de silencio, a partir de los años 80, aparecieron dos más muy amplios, los de Ernst Stauffer y Hans Hutter, que, a diferencia de las memorias de antiguos miembros de la legión extranjera, buscaban la com-

17 KOLLER, Christian: «Fremder Kriegsdienst als biographische Krise? Memoiren schweizerischer Fremdenlegionäre und Spanienkämpfer im Vergleich» en: EPKENHAUS, Michael, FÖRSTER, Stig, HAGEMANN, Karen (ed.): Militärische Erinnerungskultur. Soldaten im Spiegel von Biographien, Memoiren und Selbstzeugnissen. Paderborn, Ferdinand Schöningh 2006, pp. 169-170.

18 ULMI, Nic, HUBER, Peter: Les combattants suisses en Espagne républicaine (1936-1939). Lausanne, Antipodes 2001, pp. 51-82.

19 ULMI, Nic, HUBER, Peter: Op. Cit., pp. 231-246. 
prensión del lector no sólo con la decisión individual de participar en una guerra extranjera, sino también con la causa que defendían.

Los ex-combatientes suizos fundaron, tras su regreso a Suiza, una asociación que se esforzó, entre otras cosas, por conseguir que se construyese un monumento en recuerdo a su lucha. En 1976 se colocó una placa conmemorativa en la Casa del Pueblo de Zúrich y en 1978 se erigió un monumento con los nombres de los voluntarios del Ticinio, el cantón suizo de habla italiana, en Monte Ceneri. En 1986 se colocó en Ginebra otra placa conmemorativa y en 2000 se inauguró una escultura de cuatro metros de altura, financiada por la ciudad de Ginebra, en recuerdo de los voluntarios suizos. En 2003, una plaza en La Chaux-de-Fonds se denominó «Plaza de las Brigadas Internacionales».

El recuerdo de la participación en la Guerra Civil española se relacionó desde un principio con la reivindicación de una rehabilitación política y jurídica de los brigadistas. En 1938, un comité logró juntar en pocas semanas 80.000 firmas para una petición de amnistía, que, sin embargo, fue rechazada en una votación ajustada en el Parlamento federal. Sólo desde los años 70 comenzó a haber nuevas iniciativas encaminadas a una rehabilitación jurídica, que hasta ahora han fracasado siempre (en los años 1978, 1982, 1989, 1991 y 1999). En 1986, con motivo de cumplirse 50 años del comienzo de la guerra, el consejero federal Otto Stich envió, en su calidad de miembro del gobierno, unas palabras de reconocimiento a los brigadistas suizos. En la última reunión de la asociación de ex-brigadistas suizos en 1994 estuvo presente la consejera federal Ruth Dreifuss, que posteriormente escribió el prólogo a las memorias de Hans Hutter. ${ }^{20}$ En 2006, el parlamentario socialdemócrata Paul Rechtsteier ha lanzado una nueva iniciativa para conseguir la rehabilitación de los brigadistas suizos sobre la que el Parlamento suizo aún no ha decidido. ${ }^{21}$

\section{HANS HUTTER}

Hans Hutter nació en Winterthur en 1913. Tras su paso por la escuela secundaria realizó un aprendizaje como mecánico ajustador. A los 19 años terminó su formación militar obligatoria en la escuela de reclutas. A continuación se formó como mecánico de coches en 1933. Viajó por Suiza en bicicleta en búsqueda de un trabajo que encontró en La-Chaux-de-Fonds en un taller de reparación de coches. Esta pequeña ciudad de la industria relojera tenía una importante tradición obrera y anarquista desde el siglo XIX. En La-Chaux-de-Fonds, Hans Hutter entró en contacto con grupos de izquierda y formó parte del Frente Antifascista fundado por el profesor de instituto Paul-Henry Jeanneret. Jeanneret dio una conferencia

20 KINDLIMANN, Adrian: Schweizer im Spanischen Bürgerkrieg. Zúrich, Militärakademie an der ETH Zúrich 2004, pp. 40-50.

21 http://www.spanienfreiwillige.ch/ 
sobre el comienzo de la Guerra Civil española en 1936 y comentó que, entre otros tipos de ayudas, a los republicanos españoles les hacían falta mecánicos de automóviles. Hans Hutter decidió poco después apoyar a la República frente a Franco. En septiembre de 1936 viajó a Barcelona a pesar de la prohibición del gobierno suizo. ${ }^{22}$

Hans Hutter era un pacifista y, en principio, no quería luchar en el frente, sino poner sus conocimientos de mecánico al servicio de la causa republicana reparando coches. Pero su formación militar, fruto de diez semanas en la escuela de reclutas del ejército suizo, le permitía saber utilizar bien las armas y, al poco tiempo de su llegada a Barcelona, fue a luchar al frente de Aragón. Más tarde fue caporal, instructor y comandante de un cuerpo de guardia en Barcelona en 1938. En agosto de 1938 volvió a Suiza donde fue condenado por «participación en un servicio militar extranjero" a una pena de cárcel, por la que tuvo que estar dos semanas en prisión, y a la pérdida de sus derechos políticos durante varios años. ${ }^{23}$ En 1942 conoció a la que luego se convirtió en su esposa, Nelly Hutter. En 1947 sacó un título de maestría en mecánica de automóviles y unos años más tarde abrió con sus hermanos su primer taller de reparación de coches. Murió el 12 de diciembre de 2006.

\section{EL DOCUMENTAL SOBRE HANS HUTTER: MEMORIAS, HISTORIA ORAL Y FOTOGRAFÍAS COMO FUENTES}

Nuestro documental se centra en las narraciones orales y las fotografías de Hans Hutter. En la bibliografía sobre la Guerra Civil, la fotografía privada no ha sido aún muy tratada, pero sí se encuentran obras muy importantes sobre el fotoperiodismo de la época, como por ejemplo los estudios de Caroline Brothers y Gerhard Paul. ${ }^{24}$ Ambos autores se han ocupado del uso de la fotografía de prensa como fuente histórica sobre la guerra. Brothers se interesa sobre todo por las "confesiones involuntarias» de los fotógrafos sobre su propia sociedad y por el poder de las imágenes. En los años 30 y gracias a los avances de la tecnología, la fotografía vivió un enorme auge en la prensa y en otros campos. En revistas como Look, Life o Vu se aprecia una nueva actitud hacia la fotografía y el oficio de fotoperiodista surge en ese momento. La Guerra Civil española fue una de las primeras guerras en las que la fotografía se empleó abundantemente para informar a la opinión pública mundial. Y este hecho ha marcado la imagen de la guerra en la memoria histórica hasta hoy.

22 HUTTER, Hans, Op. Cit., pp. 7-23.

23 HUTTER, Hans, Op. Cit., pp. 308-318.

24 BROTHERS, Caroline: War and Photography. A Cultural History. London, Routledge, 1997; PAUL, Gerhard: Bilder des Krieges-Krieg der Bilder. Die Visualisierung des modernen Krieges. Paderborn, Ferdinand Schöningh, 2004. 
Las fotos de Hans Hutter no fueron tomadas para ser publicadas en la prensa y no pueden, por lo tanto, ser analizadas conjuntamente con textos de artículos periodísticos o pies de fotos. Lo que ayuda a interpretarlas son sus memorias y las partes de su álbum privado que se han conservado. En sus memorias se publican algunas de sus fotos, pero se utilizan fundamentalmente como ilustración de la narración, y no son abordadas explícitamente como un tema en sí. Las memorias no explican, por ejemplo, cómo y cuándo fueron tomadas las fotografías que se incluyen en la publicación. Aún así, lo narrado en las memorias permite a menudo indirectamente localizar los contextos generales en que surgieron las fotografías, especialmente cuando describen los acontecimientos con los que éstas se relacionan de algún modo. Así, Hans Hutter narra, por ejemplo, de manera bastante detallada, cómo vivió el entierro del anarquista Buenaventura Durruti en Barcelona, un acontecimiento, en el que sacó muchas fotografías. Sin embargo, no hace referencia explícita a las mismas.

En parte se conservan, como hemos visto, partes de su álbum privado de fotografías, que Hans Hutter fue elaborando durante los años posteriores a la Guerra Civil, cuando vivía ya en Suiza. Las hojas sueltas del álbum no son fáciles de datar. Durante años se ocupó de la Guerra Civil en privado y sólo a partir de los años 70 se atrevió a hablar en público sobre su participación en ella. En las hojas del álbum $\mathrm{y}$, a veces, en la parte de atrás de las fotografías, se encuentran indicaciones que permiten datarlas. En algunos casos, estas indicaciones son de su propia mano, y, en otros, provienen de su amigo André Herrmann, que le ayudó a redactar sus memorias. Hans Hutter explica frecuentemente en ellas quiénes aparecen en las fotografías y en qué situación se encontraba cuando tomó la fotografía, y reflexiona sobre la guerra y la paz en términos más generales.

En nuestro documental nos hemos concentrado en algunas de esas fotografías. No sólo queríamos mostrar cómo se pueden contextualizar gracias a las memorias y al álbum, sino también pedirle que hablase sobre ellas ante la cámara. Durante el rodaje siempre nos esforzamos por no fatigarlo, teniendo muy en cuenta su avanzada edad y su estado de salud. Hans Hutter fue extraordinariamente generoso con todo el equipo del documental y quiso colaborar siempre que podía, aunque en muchas ocasiones no le resultaba fácil narrar sus experiencias. Las fotos servían muchas veces de estímulo para sus narraciones orales y le ayudaban a reavivar sus recuerdos.

La película está construida cronológicamente y presenta las fotos indicando su datación siempre que es posible. Lo que se pretende es que no sirvan simplemente de ilustración de la narración, sino que se constituyan en objeto de análisis y de reflexión para el espectador. La voz en off comenta y explica su carácter de fuentes para la historia de la Guerra Civil, completando así lo que cuenta su autor. A continuación presentaré algunos ejemplos de las fotos empleadas en el documental y del modo de presentarlas. Las limitaciones derivadas de la duración del documental y de su ritmo narrativo nos obligaron a escoger sólo algunas de sus muchas 
fotografías, de las que aquí sólo presentaré unas pocas. A su muerte, todas fueron donadas al Archivo de Historia del tiempo presente del Instituto Politécnico de Zúrich $^{25}$, en el que han comenzado los trabajos de catalogación.

Uno de los temas que solemos tratar con los alumnos cuando comentamos con ellos la película es el papel de las emociones y los sentimientos en la historia oral. Para ello nos centramos en dos aspectos: por un lado, el hecho de que las entrevistas enfrentan al historiador con la evidencia de que la Historia tiene para quien la escribe una faceta cognitiva, pero también una emocional, sobre la que es necesario reflexionar abiertamente para saber adaptarla a los fines científicos de la disciplina. Por otro, la expresión que tanto en las imágenes como en las palabras de las fuentes documentales reciben los sentimientos de los actores históricos. ${ }^{26}$ Para ello tomamos como ejemplo distintas escenas de la película y en particular las fotografías que en ella aparecen. A continuación mostraré cómo se puede abordar este tema partiendo de las instantáneas de Hans Hutter.

En el viaje a España, Hans Hutter comenzó a fotografiar lo que veía: algunos lugares y paisajes del Sur de Francia, cuyos nombres solía apuntar luego en el álbum. Su viaje en tren estuvo acompañado de varias dificultades, entre otras en el paso de la frontera española. Las fotografías de su llegada a Barcelona en septiembre de 1936 aparecen con comentarios que se encuentran a menudo en la parte de atrás. En sus memorias se advierte la atmósfera de la ciudad y sus primeras vivencias en España: por un lado, el compromiso de los brigadistas que va conociendo y la amistad que pronto entabla con alguno de ellos; por otro, sus quejas sobre lo exagerado de algunas acciones propagandísticas de republicanos y anarquistas que contrastaban, a su modo de ver, con su poca voluntad de ir a luchar al frente. ${ }^{27}$ Una imagen de septiembre de 1936 muestra la fachada del Hotel Colón, la sede del PSUC, en la que se ven grandes imágenes de Lenin y Stalin. Hans Hutter utilizó su foto como postal y escribió por detrás: «Hotel Colón, sede del PSUC, en la ventana marcada estoy sentado ahora mismo y escribiendo. Tengo que buscar una habitación para unos camaradas, si no te hubiese escrito más». No sabemos a quien iba dirigida, pero sí nos contó que normalmente enviaba las cartas a unos amigos en Francia, que, cuando éstas iban dirigidas en realidad a amigos suizos, se las mandaban ellos a su vez desde Francia, para que los aduaneros y empleados de correos suizos no viesen un remite de España, que les hubiese puesto sobre aviso. Desde el comienzo, las emociones y los sentimientos se articulan en torno a las vivencias políticas de Hans Hutter.

25 http://www.afz.ethz.ch/afz/newsdetail.html

26 Sobre los sentimientos como objeto de estudio de la Historia véase: ROSENWEIN, Barbara $\mathrm{H}$.: «Worrying about Emotions in History» The American Historical Review 107/3, (2002), pp. 821-845; BOURKE, Joanna: «Fear and Anxiety. Writing about Emotion in Modern History» History Workshop Journal 55 (2003), pp. 111-133.

27 HUTTER, Hans, Op. Cit., pp. 24-43. 
Otra fotografía de esa primera etapa muestra a cuatro brigadistas que luego lucharon con Hans Hutter en diferentes lugares. Están «de paseo dominical por la Rambla de las flores». Hutter escribió en su álbum al lado de esta foto el nombre y el triste destino de los que aparecen en ella, subrayando así el compromiso político que les llevó a participar en la guerra:

«Paseo dominical por la Rambla de las flores. El primero de la izquierda es Noldi Pulver de Zúrich, que estuvo conmigo en el carro de combate. El segundo, un alemán del norte, a quien los de la undécima Brigada llamaban Papá. El tercero fue herido cerca de Tardienta. Era de Stuttgart.

El cuarto, un austriaco muy querido, cayó durante la desafortunada defensa de una trinchera en Las Rozas." La amistad y el recuerdo se entremezclan en sus comentarios de las fotos en las que aparecen los compañeros y combatientes que él llegó a apreciar más. Al recordar su destino suele hacer alusión a los sentimientos propios de la solidaridad masculina que impregna los ideales de los soldados que lucharon juntos o que compartieron sus anhelos de victoria frente a las tropas enemigas.

El antiguo convento del Sagrado Corazón en Sarriá era el lugar de residencia de la centuria Thälmann. Hans Hutter vivió allí a finales de septiembre de 1936 y conoció entre otros a Hans Beimler. Beimler era comisario y el responsable de los brigadistas alemanes. A pesar de su desconfianza hacia los «funcionarios» comunistas, a Hans Hutter le «sorprendió agradablemente» el encuentro con Beimler, que le impresionó como persona ya en esta primera ocasión. En sus memorias describe con precisión sus experiencias en este convento convertido en cuartel, que fue el primer lugar donde empezó a entablar amistades con jóvenes de otros países venidos a luchar en la Guerra Civil. ${ }^{28}$

El 24 de septiembre, los brigadistas fueron llevados al cuartel Carlos Marx y un día después salieron para el frente de Aragón, en donde Hutter se hizo miembro de un grupo que tenía un carro de combate. Se trataba en realidad de un camión americano que había sido recubierto con placas de acero. Hans Hutter le llama en su álbum «mi carro de combate», porque ayudó a repararlo. Con la utilización del posesivo «mi» subraya su relación afectiva con este carro de combate con el que participó en sus primeras luchas en España. ${ }^{29}$ El carro simbolizaba para él, además, su ambivalente relación con la guerra, pues su intención inicial al partir de Suiza era ayudar en el lado republicano con sus conocimientos de mecánico reparando coches y camiones para las tropas pero sin participar directamente en los combates. Se sentía un pacifista, y al mismo tiempo quería ayudar a combatir el fascismo en Europa.

Hasta mediados de noviembre, Hans Hutter luchó en la Sierra de Alcubierre en el frente de Aragón. En noviembre volvió a Barcelona de vacaciones y participó en

\footnotetext{
28 Ibidem.

29 HUTTER, Hans, Op. Cit., pp. 44-102.
} 
el entierro del anarquista Buenaventura Durruti el 22 de noviembre. En sus memorias describe sus impresiones de este entierro: grandes masas participaron en él y Hans Hutter se dio cuenta en esa ocasión de la fuerza del apoyo de los anarquistas en Barcelona. En sus conversaciones con los anarquistas, Hans Hutter trataba de convencerles de la necesidad y ventajas de organizarse bien y de la unión de todas las fuerzas de la República. ${ }^{30}$ En nuestro documental hemos recogido varias de estas fotos en las que se advierte cómo los rituales laicos de los anarquistas transmitían los sentimientos de tristeza y dolor asociados al luto.

A comienzos de diciembre de 1936, Hans Hutter fue a Albacete y estaba allí precisamente cuando tuvo lugar el entierro de Hans Beimler. ${ }^{31}$ La muerte de Beimler le afectó especialmente porque le conocía y apreciaba. Fue asesinado el 28 de noviembre. Al lado de la foto del entierro Hans Hutter anotó en su álbum:

«Albacete, 2 de diciembre de 1936. El último viaje de Hans Beimler. Un comunista como todos los comunistas deberían de ser, hablaba español, un hombre simpático ¡No era ningún estalinista!»

Hutter perteneció al batallón Thälmann de la Brigada XII y formó parte en Madrid de la compañía de ametralladoras. Participó en las batallas del barrio de la Universidad y escribió en sus memorias que nunca había visto hasta entonces tal cantidad de armas diferentes. Además, en ell describe las destrucciones que las bombas causaban en la ciudad. ${ }^{32}$

Estuvo en Las Rozas, luego en febrero de 1937 en la batalla del Jarama, una de las más sangrientas de la Guerra Civil, y más tarde en Guadalajara, cuando los «voluntarios» italianos intentaron sin éxito tomar Madrid desde el norte. ${ }^{33}$ En una de las entrevistas recogidas en el documental, narra algunas de sus vivencias en estas batallas mostrando planos que él mismo había dibujado de los lugares en que estas tenían lugar.

Las fotografías de Hans Hutter no se dirigen a un gran público, al contrario de las películas de propaganda de aquella época, de las que se ven en determinados momentos algunas escenas en el documental, o de las fotografías de la prensa. Sus fotos ilustran sus experiencias y dan su visión subjetiva de la guerra. Por tanto, son representados con frecuencia sus amigos y camaradas, pero también los coches, los fusiles, los tanques y las casas destruidas,

Las calles de las ciudades y aldeas, los funerales de famosos combatientes republicanos y los cadáveres de las tropas enemigas. En una hoja pegó las fotos que había tomado en la batalla de Guadalajara. Las ordenó sobre dos páginas: las fotos de la guerra y las fotos de la paz. A pesar de no escribir nada en particular so-

\footnotetext{
30 HUTTER, Hans, Op. Cit., pp. 103-109.

31 HUTTER, Hans, Op. Cit., pp. 110-118.

32 HUTTER, Hans, Op. Cit., pp. 119-123.

33 HUTTER, Hans, Op. Cit., pp. 157-187, 197-229.
} 
bre este contraste en el álbum, sus reflexiones sobre la paz y la guerra en sus memorias, sus dudas y sus descripciones de la brutalidad de esta y otras batallas dan un sentido especial a esa página con las fotos de Guadalajara.

Desde mayo hasta julio de 1937 Hans Hutter cursa su formación de oficial en Pozo Rubio. Junto con una formación táctica y maniobras prácticas, los aspirantes frecuentan un curso intensivo de español. En los ratos libres tienen lugar discusiones políticas en las cuales Hutter polemiza contra el entusiasmo de los comunistas alemanes en favor de la Unión Soviética, e intenta hacerles ver las ventajas del sistema político suizo. El 1 de julio de 1937 Hutter aprueba el examen de oficial del ejército como el mejor de su curso. Su hermano Max también finaliza su formación de suboficial, siendo también éste el mejor de su curso. Tan solo unas semanas más tarde Hans Hutter adquiere un puesto de instructor. ${ }^{34}$ Una de las fotos que conservó Hans Hutter, le muestra como oficial de las Brigadas Internacionales. El retrato contrasta por su austeridad y seriedad con los retratos que conservaba de sus primeros días en Barcelona, que muestran casi siempre a un joven sonriente y comunicativo.

A finales de julio de 1937 Hans Hutter se entera de que su hermano Max ha caído en la ofensiva de Brunete. A pesar de ello su nombre no aparece en la lista de caídos. Tras dos dolorosas semanas, Hans Hutter tiene la certeza del fallecimiento de su hermano, muerto por la metralla de una granada alemana. En los siguientes meses Hans Hutter continúa en su función de instructor. ${ }^{35}$ La muerte de su hermano se convirtió para él en uno de los sucesos más traumáticos de la guerra, como narra en sus memorias. Algunas de las entrevistas que realizamos con él para el documental fueron rodadas en su cuarto de trabajo en su casa, donde guardaba sus libros, sus escritos, sus fotografías y numerosos objetos personales. Tras él se ve en esas escenas una serie de acuarelas suyas decorando la pared, algún póster conmemorativo de acontecimientos culturales y una hoja escrita en letra grande propia de una impresora de ordenador, en la que se puede leer un texto en alemán en referencia a su hermano: «Max, mientras alguien piense en ti, seguirás vivo". Cuando mostraba las fotos de Max, algunas de las cuales hemos recogido en el documental, hablaba de él con cariño y orgullo. Con los alumnos comentamos tras la visión del documental, cómo esta contextualización de las fotos de su hermano influye en la percepción que el espectador tiene de estas instantáneas y de su función en la labor de recuerdo del pasado personal.

Un tratamiento aparte merecería la utilización que hacemos en el documental de las películas propagandísticas del legado del cineasta suizo Robert Risler. Baste con decir que estas películas fueron proyectadas con el fin de recaudar fondos para la ayuda humanitaria dirigida a la República española que prestó el Schweizerisches Arbeiterhilfswerk, una organización no gubernamental surgida en

34 HUTTER, Hans, Op. Cit., pp. 241-259.

35 HUTTER, Hans, Op. Cit., pp. 260-282. 
estos años y ligada a los sindicatos y al Partido Socialista Suizo. ${ }^{36}$ El legado de Robert Risler se encuentra en el Schweizerisches Sozialarchiv de Zúrich y estas películas se pueden consultar también en la Cinématheque de Lausana. En el documental algunas de estas escenas nos sirven, entre otras cosas, para ilustrar las partes en las que explicamos con ayuda de la voz en off, cómo se desarrolló la Guerra Civil en líneas generales, cuando estas referencias resultan necesarias para entender mejor los hechos narrados por Hans Hutter en las entrevistas. En otros casos el texto leído por la voz en off se centra en el carácter propagandístico de las escenas para aclarar qué función tenían estas imágenes en la época.

\section{CONCLUSIÓN}

Las metodologías de enseñanza tradicionales pueden verse reforzadas por las nuevas tecnologías para lograr una formación universitaria basada, al mismo tiempo, en la interacción con el alumno y en la distribución por Internet de materiales y herramientas de aprendizaje y de comunicación. Los medios audiovisuales son un complemento eficaz de la lectura y la elaboración de textos y de la comunicación oral en la práctica docente, y adquieren especial importancia ante los retos derivados de la renovación de la enseñanza universitaria que lleva consigo la reforma de Bolonia. Tanto para la transmisión de competencias como para la de contenidos, estos medios ofrecen posibilidades aún no del todo exploradas en el ámbito de la enseñanza de la Historia. En combinación con las estrategias didácticas propias de las plataformas de e-learning, como la creación de foros de debate, las películas formativas y los documentales pensados para un público universitario, favorecen el diálogo, la discusión y la reflexión sobre temas históricos tanto por escrito como oralmente. Por otro lado, cuanto más ligados estén los medios audiovisuales a la realidad académica circundante del alumno, mayores son las posibilidades de éxito en el proceso de aprendizaje. Por ello es necesario encajar los mensajes de los medios audiovisuales en un programa común orientado a transmitir conocimientos, aptitudes y destrezas: la discusión sobre conceptos fundamentales de la Historia, la profundización en el empleo de instrumentos de trabajo en bibliotecas y archivos accesibles al alumno, la mejora de la técnica en la presentación de las ponencias en las aulas, el análisis de fuentes de tipo audiovisual o el acercamiento a un tema concreto como la historia oral de las Brigadas Internacionales en la Guerra Civil española contando con fotografías y películas de la época, son algunos de los ejemplos aquí presentados y que se basan en las experiencias realizadas en estos últimos años en el Seminario de Historia de la Universidad de Zúrich.

36 SCHMIDLIN, Antonia: «La neutralité de l'aide suisse a a l'Espagne lors de la guerre civile» en: CERUTTI, Mauro, GUEX, Sébastien, HUBER, Peter (ed.): La Suisse et l'Espagne de la République à Franco (1936-1946). Relations officielles, solidarités de gauche, rapports économiques. Lausanne, Antipodes 2001, pp. 140-141. 


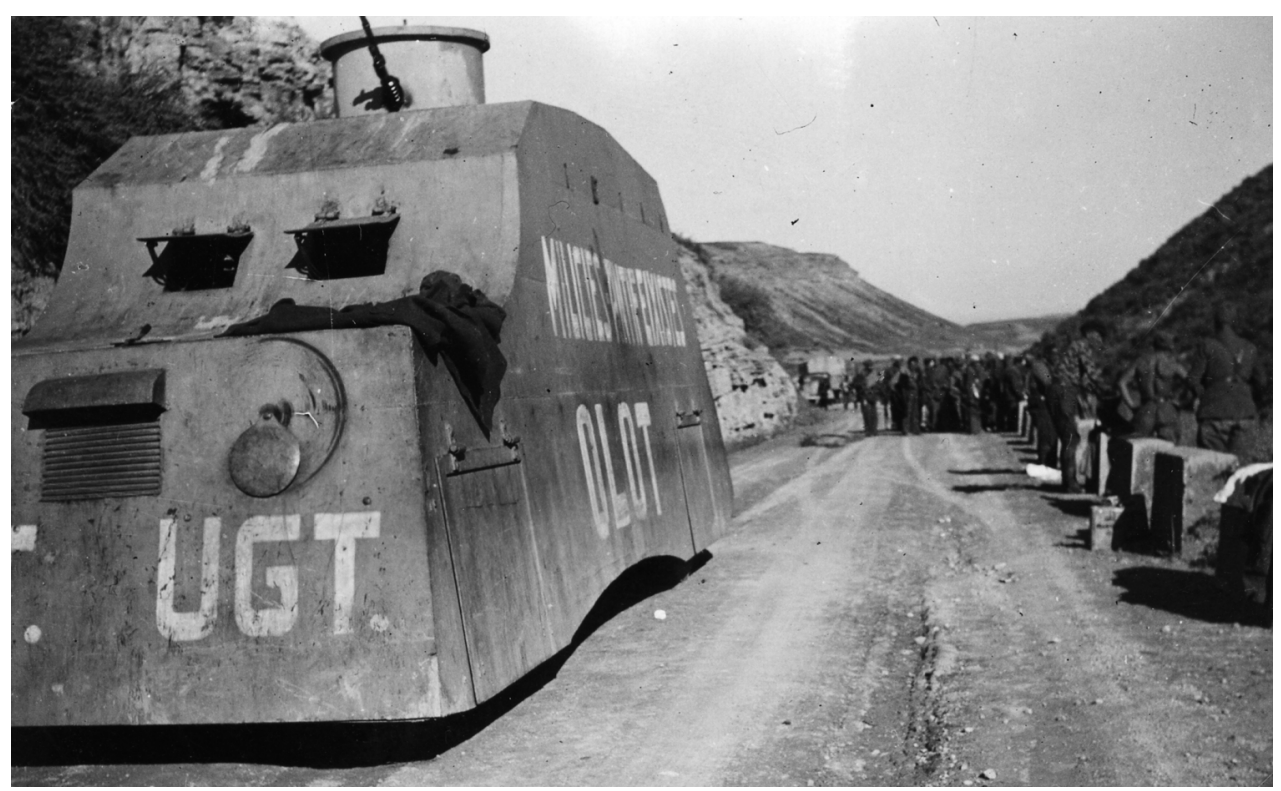

Carro blindado en el paso de Alcubierre, noviembre de 1936.

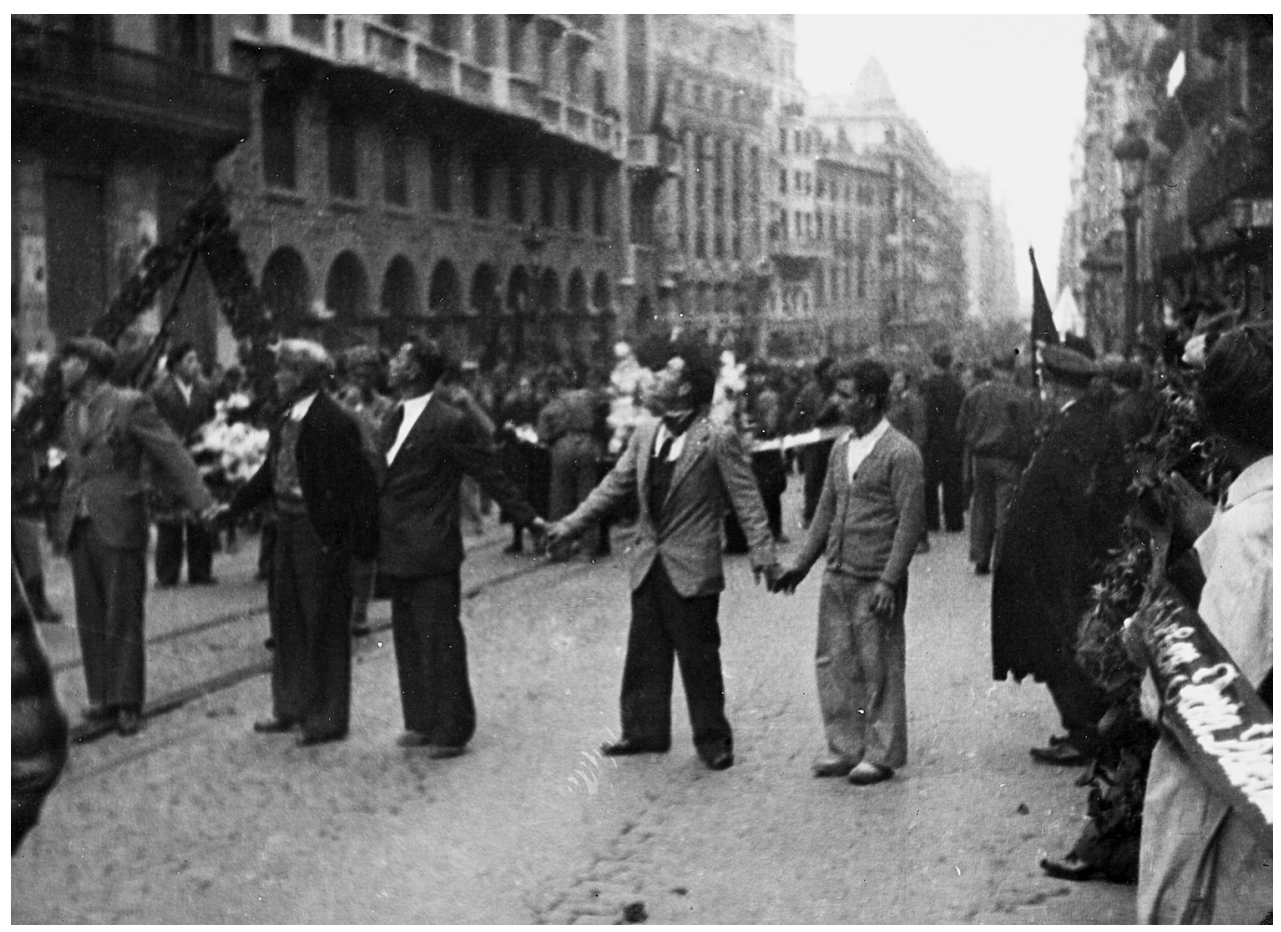

Entierro de Durruti. 


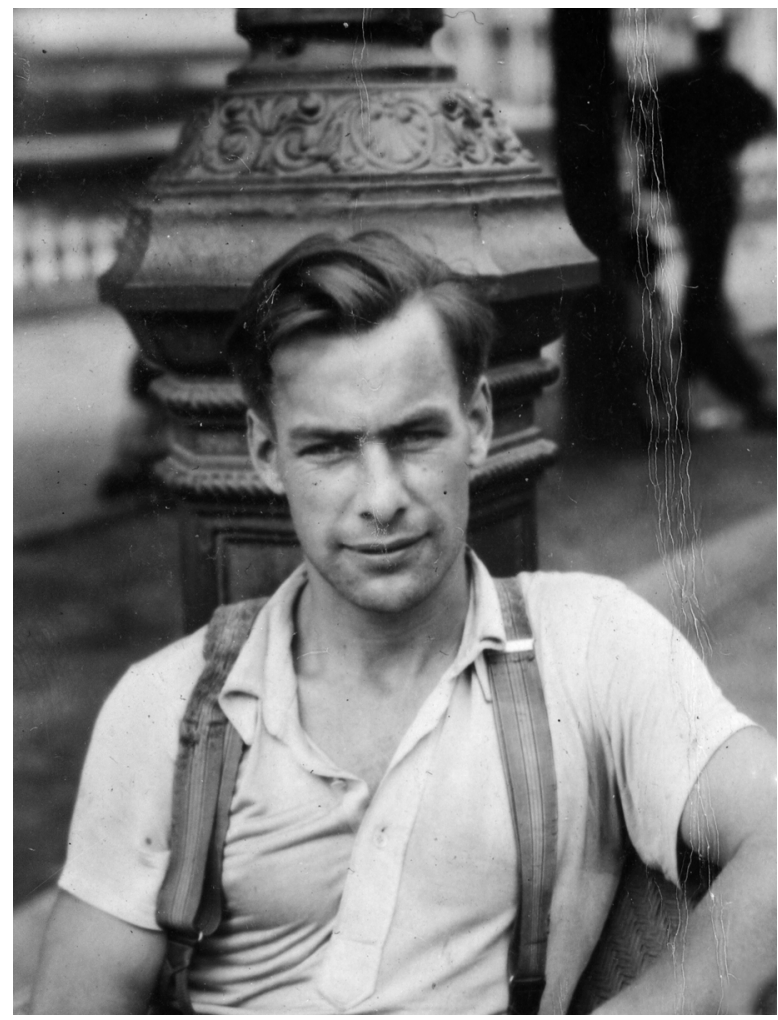

Hans Hutter.

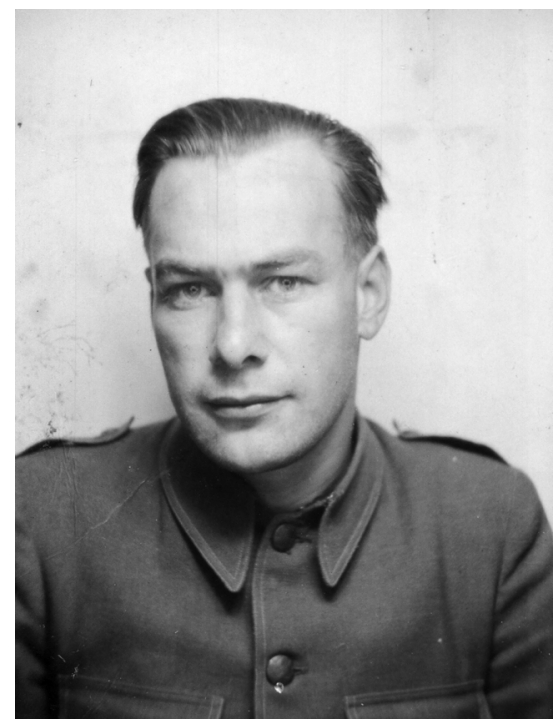

Hans Hutter. 


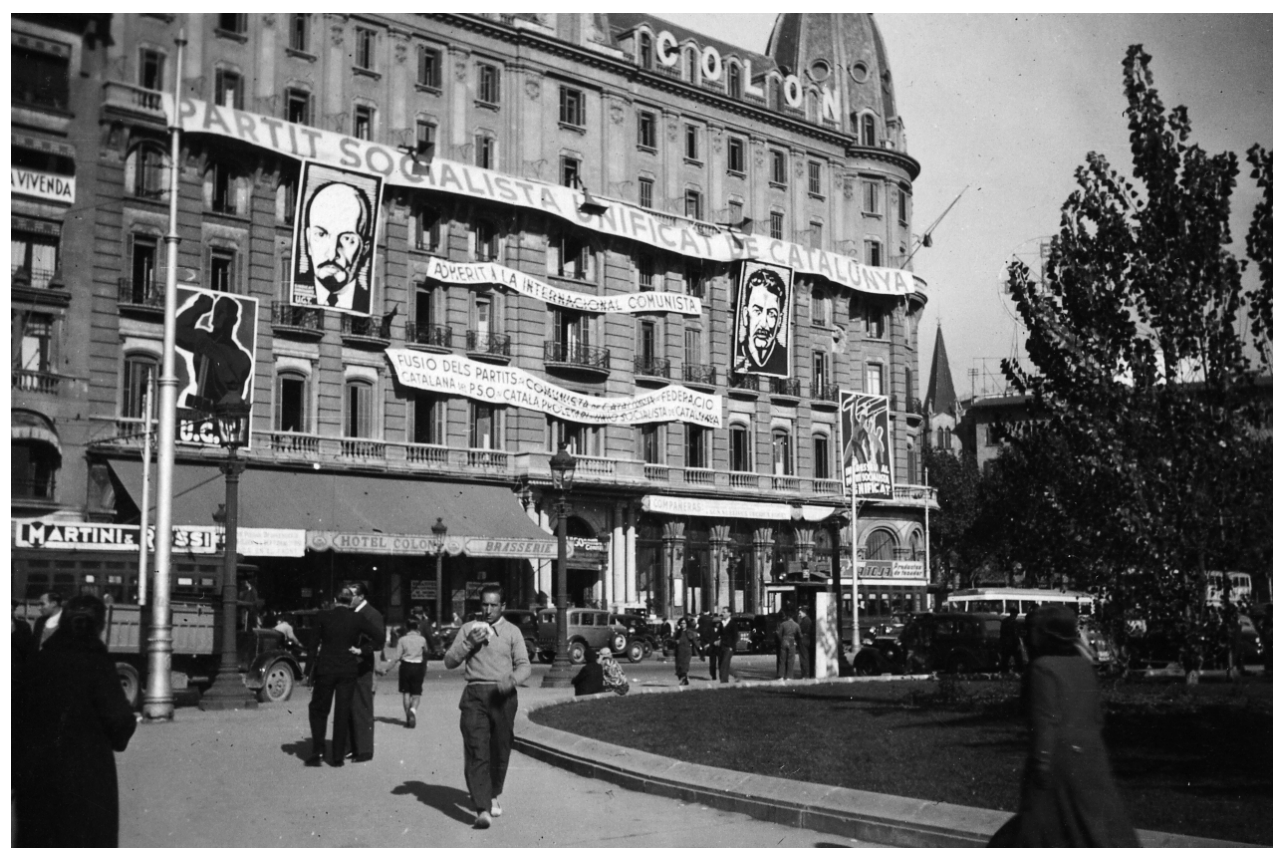

Hotel Colón, Barcelona, finales de 1936.

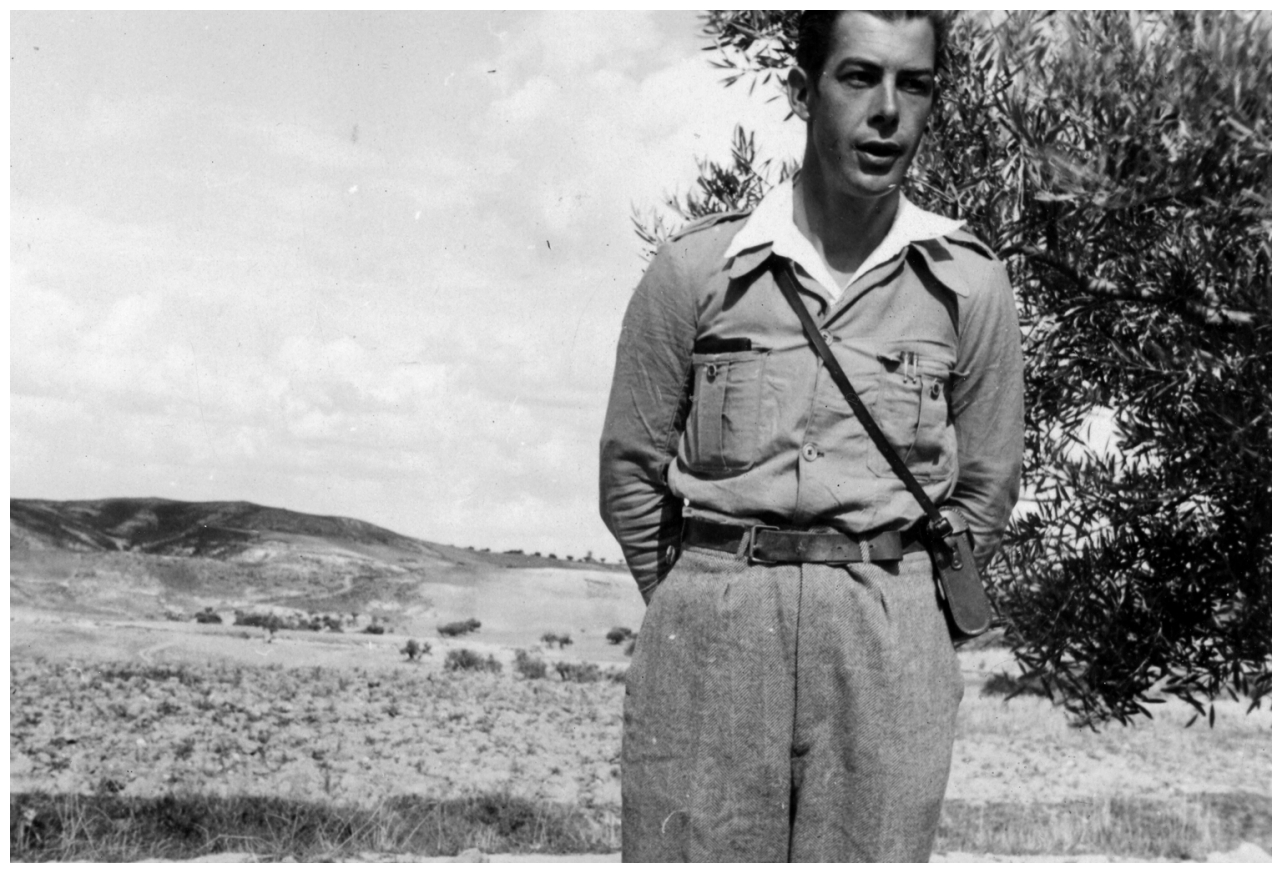

Max, el hermano de Hans Hutter. 


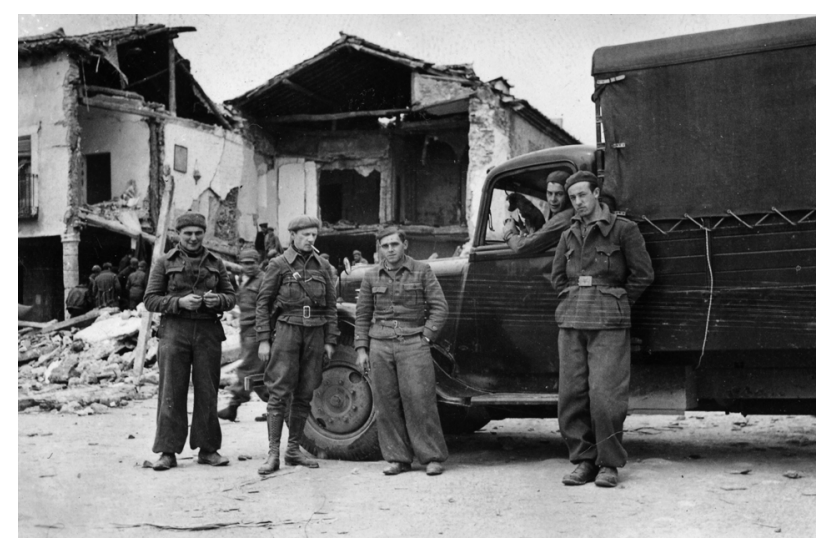

Torija, finales de marzo de 1937.

Todas las fotos proceden del archivo personal de Luis Calvo Salgado. 